\title{
Relative costs and reactions to threats'
}

SVENN LINDSKOLD, THOMAS BONOMA, and JAMES T. TEDESCHI, University of Miami, Coral Gables, Fla. 33124

A 3 by 3 by 2 design was employed in which 72 male $S$ s were assigned across three levels of a linearly transformed Prisoner's Dilemma Game (PDG) payoff matrix, three levels of punishment magnitude, and two levels of threat credibility. Occasional threats of a loss of points were sent by $a$ simulated player during 150 PDG trials. Unanticipated effects of both matrices and punishment magnitude were obtained on overall cooperation. An effect of matrices was obtained on compliance to threats. Postimpressions of the simulated source were that the $10 \%$ credible threatener was perceived as strongly potent, while the highly credible source was considered mildly impotent.

The Prisoner's Dilemma Game (PDG) was modified by Horai \& Tedeschi (in press) to include a reiterated threat message transmitted to the $S$ from a simulated player. They found a positive linear relationship between compliance to the threat and threat credibility-levels of which were established by varying the proportion of times that defiance was punished. Results also showed that high punishment caused more compliance than either moderate or low levels of costs. The fact that moderate costs did not produce more compliance than low costs was explained by comparing the competitive advantage accruing to the exploitative source when $S$ complied against the costs imposed upon the target $S$ for defiance. Tedeschi, Horai, Lindskold, \& Gahagan (1968) also found that levels of punishment for noncompliance which did not exceed the competitive advantage had no effect on compliance and cancelled the effects of credibility as well.

In order to manipulate competitive advantage for systematic study, without causing response differences within the PDG which are attributable to the use of different matrices, linear transformations of all payoff values can be made (Steele \& Tedeschi, 1967; Rapoport \& Chammah, 1965; Jones, Steele, Gahagan, \& Tedeschi, 1968). The present design employed three matrices involving different values for competitive advantage-high, moderate, and low punishment magnitudes, and high and low credibility levels.

\section{SUBJECTS}

Seventy-two male Ss partially fulfilled an introductory psychology course require- ment by participating in the experiment and were randomly assigned to the 18 treatment conditions.

APPARATUS
The game apparatus used has been more fully described by Horai \& Tedeschi (in press). Briefly, the S's game board consisted of: (a) the payoff matrix; (b) pushbuttons for Choice 1 (cooperative) and Choice 2 (competitive) strategy selections; (c) printed messages, each with a signal light to indicate receipt and pushbutton for transmission; (d) add-subtract cumulative counters from which the $S$ could read the point totals for both players; and (e) a series of prompter lights to indicate when to make strategy selections, send communications, and to signal punishment options. The three matrices used had the following values, corresponding to the $R, T, S$, and $P$ Payoffs $2: 4,5,-5,-4 ; 8,10,-10,-8 ; 16$, $20,-20,-16$.

\section{PROCEDURE}

Subjects signed up in pairs and care was taken to maintain the impression that each $S$ was playing another male in an adjoining cubicle. While alone, Ss read the instructions which specifically stated that their goal was to obtain as many points as possible. When a message was sent to an $S$, he was to send a reply; but he could not initiate communications. The one message available to the simulated player (SP) was: "If you don't make Choice 1 on the next trial, I will take $x$ points away from your counter." The S had a choice of three reply messages: I will make Choice 1 on the next trial; I will make Choice 2 on the next trial; I do not wish to disclose my intentions.

A total of 54 of the 150 trials, an average of 3.6 per block of 10 trials, were programmed as potential threat trials. A criterion of 10 unsuccessful threats (noncompliances) was established for each S so that fixed cumulated credibilities could be assigned according to the experimental condition. The $\mathrm{E}$ attempted to establish one unsuccessful threat per block of 10 trials; if the $S$ complied to all threats sent in a block the $\mathrm{E}$ attempted to achieve two noncompliant responses in the next block to catch up to the pace, but never were more than two noncompliant responses obtained in a single block. Potential threat trials which were not used were just like any other nonthreat trial from the S's point of view. Once the criterion of 10 noncompliances was achieved, the remaining PDG trials to 150 were played without message exchanges. The $10 \%$ credibility condition was established by punishing only the fifth noncompliance and $90 \%$ credibility was established by punishing all noncompliances but the fifth one. The SP always made a competitive response on a threat occasion so that $S$ always was presented with a least-of-evils choice following message exchanges. Punishment magnitudes of 5, 10, and 20 points were indicated in the threat message sent by SP, according to the S's cell assignment.

After completion of PDG play, Ss were asked to complete an "Interpersonal Impressions Test," a form adopted from the Semantic Differential of Osgood, Suci, \& Tannenbaum (1957).

\section{RESULTS AND DISCUSSION}

The dependent variable of compliance, measured indirectly as the total number of threats that had to be sent to the $S$ in order to obtain 10 occasions of a noncompliant response, proved to be a $S$ variable highly correlated with the S's overall PDG strategy selections. Therefore, a 3 by 3 by 2 multivariate analy sis of covariance was performed on this dependent variable, using the total number of threats as the covariate. ${ }^{3}$ Multivariate analysis of variance was performed on the measure of compliance and the subscale scores of the semantic differential.

\section{COMPLIANCE}

A main effect of matrices was obtained on compliance $(F=5.35, \mathrm{df}=2 / 54, \mathrm{p}<.008)$ Duncan range tests indicated that there was no difference between the 4,5 and 8,10 matrices, but there was less compliance when the 16,20 matrix was used than with either of the others $(p<.05)$.

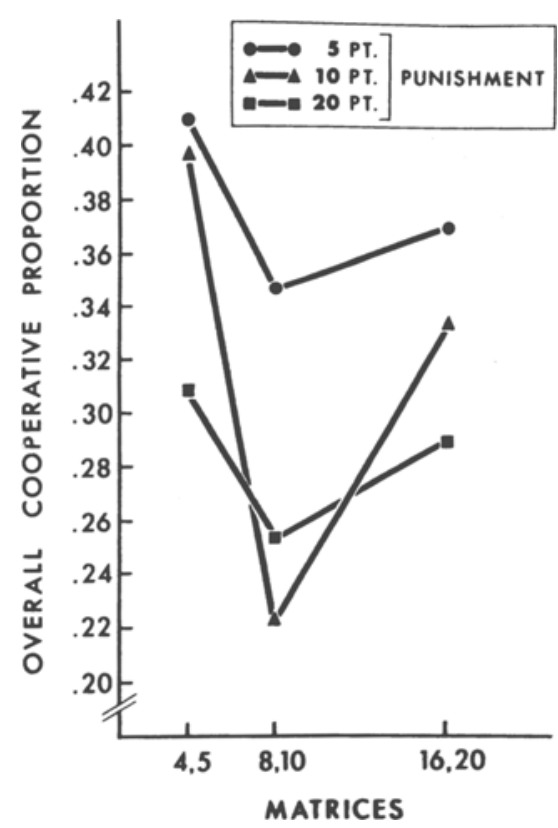

Fig. 1. The Punishment Magnutude by Matrices interaction on cooperative strategy selections, illustrating the main effect. 


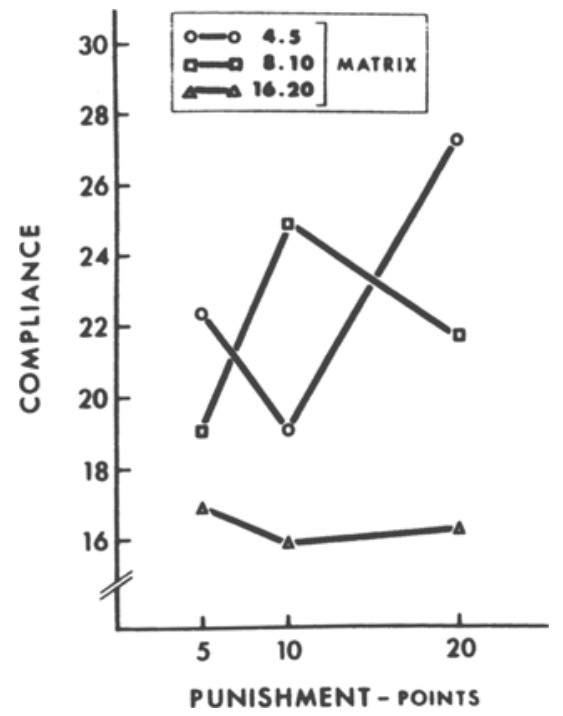

Fig. 2. Representation of means over punishment and matrix conditions with credibilities collapsed on the measure of compliance.

\section{GAME STRATEGY SELECTIONS}

There was a main effect of matrices upon the proportion of cooperative strategy selections (CP) made by $\mathrm{Ss}(\mathrm{F}=5.38$, $\mathrm{df}=2 / 53, \mathrm{p}<.007)$. There was less $\mathrm{CP}$ with the 8,10 matrix than with the 4,5 matrix ( $<<.005)$; no other comparisons were significant. Punishment magnitude also produced a main effect on $C P(F=4.80$, $\mathrm{df}=2 / 53, \mathrm{p}<.01$ ). The range tests revealed less $\mathrm{CP}$ when the threatened punishment was 20 points than when it was 5 points $(\mathrm{p}<.005)$. Figure 1 shows that the 10 -point punishment level produced intermediate cooperation, which differed from neither of the other two levels.

The relative costs hypothesis, stressing the notion of competitive disadvantage, which led to the present study, anticipated a Punishment Magnitude by Matrix interaction on compliance which was not obtained. On the other hand, neither punishment magnitude nor matrices was anticipated to have an effect on $\mathrm{CP}$, but the sharp drop in CP from the 4,5 to the 8,10 matrix is apparent even though there was no CP difference between the 4,5 and 16,20 matrices. A linear effect of punishment is suggested by these results but no clear explanation for the nonlinear effect of matrices emerges from the pattem of results. If punishment levels had interacted with matrix values in some rational fashion, a significant interaction effect would have been obtained for $\mathrm{CP}$, rather than the two main effects that actually did occur.

For comparison purposes the data on compliance is presented as collapsed over credibility, that is, by punishment magnitude and matrices (see Fig. 2). The "displaced" point in Fig. 1, which represents the 10-point punishment for the 8,10 matrix, contributed most strongly to the nonlinear effect of matrices on $C P$ and invites comparison with the same point in Fig.2. Disproportionately high compliance to the threat (resulting in suffering the exploitation payoff) on the threat trials seems to have led to a compensating low level of cooperation (attempted exploitation) on trials overall. In the case of the 4,5 Ss, however, compliance dropped at the 10-point punishment level. Disregarding considerations of credibility, 10 points in costs was the balanced situation for the 4,5 Ss; the penalty for defiance was equivalent to the disparity between the compliant S's payoff $(-5)$ and the exploiting threatener's payoff $(+5)$. As in the Horai and Tedeschi study, this equivalence led to defiance. At the comparable point for the $8,10 \mathrm{Ss}$ (20-point punishment), they were not quite so defiant, although their compliance did drop off from the 10-point level (which can be compared to the 5-point level for 4,5 Ss). Of course, there was no equivalence point for the $16,20 \mathrm{Ss}$.

The overridingly clear result on compliance is that the Ss facing the 16,20 matrix, who had the most to lose by compliance (a competitive disadvantage totaling 40 points), were consistently most contemptuous of the threat. In support of this brand of rationality, Fig. 2 shows that those 8,10 Ss who were threatened a loss of a meager 5 points we re most defiant; while the $4,5 \mathrm{Ss}$, threatened with a loss of 20 , were most compliant.

\section{SEMANTIC DIFFERENTIAL RATINGS}

A main effect of credibility on the potency dimension of the semantic differen- tial was obtained $(F=17.95, \mathrm{df}=1 / 53$, $\mathrm{p}<.001) ; 10 \%$ credibility was perceived as strongly potent $(\overline{\mathrm{X}}=3.250)$, while $90 \%$ credibility was viewed as slightly impotent $(\bar{X}=-0.490)$. This finding confirmed other results which have indicated that the withholding of punishment (Gahagan, Tedeschi, Faley, \& Lindskold, 1969; Lindskold, Bonoma, \& Tedeschi, 1969) or of rewards (Lindskold \& Tedeschi, 1969) is perceived as potent. To possess power but not to use it leads to the attribution of strength.

An interaction of Matrices by Punishment was obtained on the activity dimension $(F=2.50, \quad$ df $=4 / 53, \quad p<.053)$ and is illustrated in Fig. 3. The threatener of an amount definitely smaller or definitely larger than the pay off matrix values involved is apparently perceived as quite passive. In confirmation of what Fig. 2 suggests, the 5 . and 10-point punishments were quite influential in the compliance decisions of the $\mathrm{Ss}$ in the 4,5 matrix condition; only those two points were considered to be active.

In summary, the credibility discrimination by Ss was indicated by the semantic differential result that the least credible threatener was perceived as most potent, but compliance behavior was not affected. Likewise, punishment had its effect, not on compliance, but on the "attitude" towards cooperative play overall. The similar effect of each punishment level across matrices suggests some kind of subjective evaluation of the announced penalties that was not keyed precisely to the payoff matrix. The volatility in $\mathrm{CP}$ at the 8,10 matrix level may somehow be the result of the fact that the values of 8,10 , and the competitive

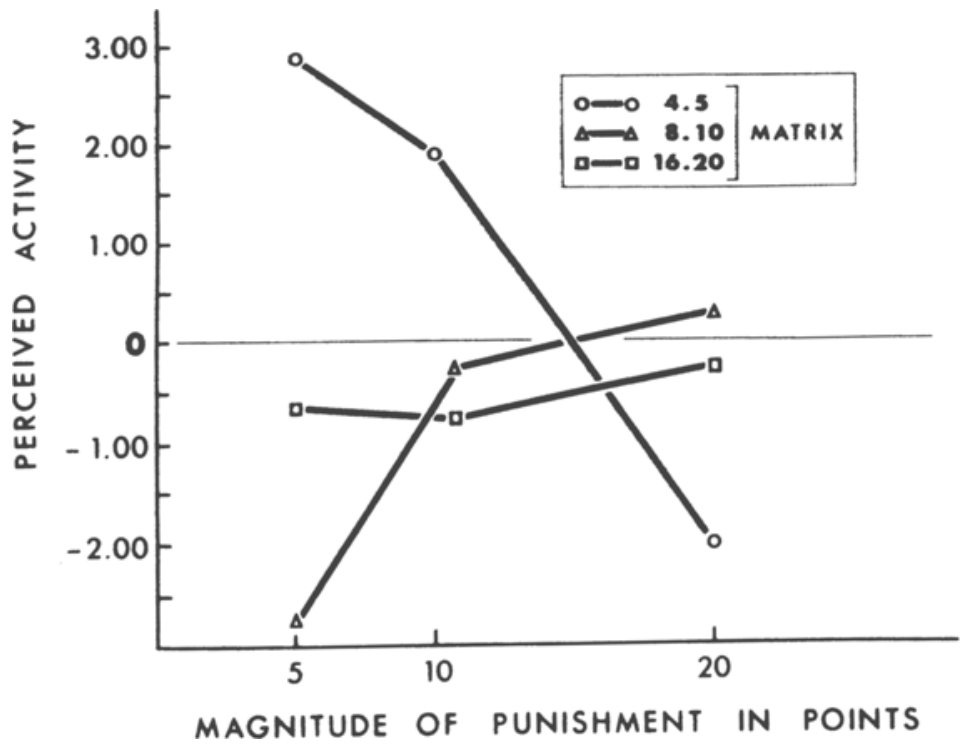

Fig. 3. The Punishment Magnitude by Matrices interaction on the Activity dimension of the Semantic Differential. 
advantage of 20 , most closely span the punishment levels of 5,10 , and 20 points. REFERENCES

GAHAGAN, J., TEDESCHI, J., FALEY, T., \& LINDSKOLD, S. Patterns of punishment and reactions to threats. University of Miami Mimeograph, 1969.

HORAI, J., \& TEDESCHI, J. The effects of credibility and magnitude of punishment on compliance to threats. Journal of Personality \& Social Psy chology, in press.

JONES, B., STEELE, M., GAHAGAN, J., \& TEDESCHI, J. Matrix values and cooperative behavior in the prisoner's dilemma game. Journal of Personality \& Social Psychology, $1968,8,148-153$.

LINDSKOLD, S., BONOMA, T., \& TEDESCHI, J. T. Reactions to a threatening simulated opponent. University of Miami Mimeograph. 1969.

LINDSKOLD, S., \& TEDESCHI, J. T. Effects of contingent promises on interpersonal conflict. University of Miami Mimeograph, 1969.

OSGOOD, C. E., SUCI, G. J., \& TANNENBAUM, P. H. The measurement of meaning. Urbana: University of nlinois Press, 1957.
RAPOPORT, A., \& CHAMMAH, A. M. Prisoner's dilemma. Ann Arbor: University of Michigan Press, 1965

STEELE, M. W., \& TEDESCHI, J. T. Matrix indices and strategy choices in mixed-motive games. The Journal of Conflict Resolution, $1967,11,198-205$

TEDESCHI, J. T., HORAI, J., LINDSKOLD, S., \& GAHAGAN, $J$. The effects of threat upon prevarication and compliance in social conflict. Proceedings, 76th Annual Convention, APA, $1968,399-400$.

\section{NOTES}

1. This research was supported in part by NIH Grant No. SB26FR07622029121902 made to the University of Miami (Florida). The authors wish to thank Joann Horai, John Powell, James Gahagan, and Thomas $F$ aley for their assistance in all phases of this study.

2. The use of this notation for representing matrix values has been adopted from Rapoport \& Chammah (1965).

3. Message related behavior was also analyzed by covariance, but no significant findings were obtained. awkward experience not only for the person making the apology but also for the person receiving it. This is especially true if there is ambiguity about who was at fault in the argument. In such a situation an apology might cause the person receiving it to experience guilt because he is aware that part of the blame is his, yet the other person is making the apology. It seems reasonable to assume that, in this situation, guilt feelings might arise which could produce tension, anger, and possibly a tendency to find the other person unpleasant.

There is also the possibility that $\mathrm{O}$ will interpret P's apology as an attempt to gain approval of his behavior from $\mathrm{O}$. By reprimanding his own behavior, the apologizer almost forces $\mathrm{O}$ to make some sort of condoning statement to him.

A final alternative is that an apology acts as a stimulus which forces recall of the unpleasant situation which preceded the apology. This could cause the recipient to feel awkward or tense.

For any of the above reasons the positive effect of an apology might be reduced. But what if the other person offers to do something for the recipient instead of apologizing to him? Such a technique should be somewhat more effective than an apology; however, it does contain several pitfalls. Perhaps the most obvious disadvantage is that offering a favor may be interpreted by the recipient as a case of one-up-manship

Another disadvantage is that the offering of a favor may be viewed by the recipient as an attempt to buy back his friendship. If this occurs, the recipient is almost certain to be annoyed by the other person and/or to feel awkward. Finally, the offer of a favor, like an apology, may call attention to a situation which is better forgotten. The offer of a favor may attach an importance to the argument which it does not deserve, and thereby increase discomfort and reduce the attractiveness of $P$.

Another technique for restoring friendly relations is for the stimulus person to ask a favor of the other person. At first glance this would seem an ineffective method. However, such a technique, if handled properly, could be quite effective. The crucial point to be considered regarding any tension relieving or ingratiating technique is how it is perceived by the person to whom it is directed. Asking a favor will be ineffective when $O$ (1) perceives the favor as large or (2) feels he is the only one available and thus that the subject had to seek his assistance. The asking of a favor will also be ineffective when it is interpreted as an obvious attempt at ingratiation. Conversely, asking a favor should yield best results when the favor is small and there are other people available that the stimulus person could ask 